\title{
Nematóides da Regiāo Amazônica. II - Nematóides parasitas e de vida livre associados à pimenta-do-reino (Piper nigrum L.) e ao cacaueiro (Theohroma cacao L.)
}

\author{
Francisco das Chagas Oliveira Freire (") \\ Ailton Rocha Monteiro ( ${ }^{*}$ )
}

\begin{abstract}
Resumo
Nesta segunda etapa do levantamento taxonômico dos nematóides da regiáo amazônica os autores apresentam os nematóides parasitas e os de vida livre associados às raízes e/ou rizosferas da pimenta-do-reino e do cacaueiro, em município do Estado do Pará. Um total de 6 gêneros e 10 espécies de nematóides parasitas e 15 gêneros de nematóides de vida livre foram catalogados. A maioria dos gêneros e espécies identificadas é, pela primeira vez, encontrada em associação a estas duas culturas na Amazônia.
\end{abstract}

\section{INTRODUÇÃo}

Plenamente adaptadas às condições amazônicas e constituindo-se numa das culturas de maior expressão agrícola regional, a pimentado-reino (Piper nigrum L.) tem contribuído de modo decisivo para a elevação das exportações nacionais máxime do Estado do Pará, principal produtor brasileiro. $\mathrm{O}$ aumento quantitativo das exportações, o acentuado crescimento dos preços no mercado internacional a par de maior exportação sob a forma de conserva, influenciaram nitidamente no interesse pela cultura não apenas na região amazônica, mas também em diversos Estados nacionais ainda que, na maioria deles, em caráter incipiente.

Por outro lado, em decorrência de suas múltiplas e lucrativas possibilidades de exploração econômica na Amazônia, a cultura do cacaueiro (Theobroma cacao L.), já extremamente ajustada às necessidades do mercado, poderá se tornar, em futuro não muito distante, um dos principais produtos da agricultura amazônica. Com efeito, as enormes áreas reconhecildas como propícias ao cacaueiro na men- cionada região, asseguram à cultura ampla possibilidade de implantaçäo e produções satisfatórias.

Tanto a pimenta-do-reino quanto o cacaueiro estão sujeitos ao ataque de inúmeros patógenos os quais podem comprometer, sobremodo, suas produtividades. A extensa lista de parasitas das referidas culturas incluem-se os nematóides, sem dúvida, responsáveis por graves danos à agricultura.

O trabalho em apreço teve por objetivo um levantamento taxonômico dos nematóides parasitas e de vida livre associados às raízes e/ou às rizosferas da pimenta-do-reino e do cacaueiro em municípios do Estado do Pará.

\section{MATERIAL E MÉTODOS}

O presente levantamento foi conduzidc nos seguintes municípios paraenses: Altamira, Belém, Benevides, Cametá, Castanhal, Curuçá, Igarapé-Açú, Santa Izabel do Pará e Tomé-Açú.

As amostras de solo e raízes foram coletadas somente em condições de campo, a uma profundidade de $30 \mathrm{~cm}$ e distância de $50 \mathrm{~cm}$ a partir do caule, para a pimenta-do-reino, enquanto para o cacaueiro a profundidade foi de $40 \mathrm{~cm}$ e a uma distância de $100 \mathrm{~cm}$ do caule. Raízes foram também coletadas, para ambas as culturas, numa quantidade aproximada de $10 \mathrm{~g}$ por planta. O material assim coletado foi acondicionado em sacos plásticos e conduzido ao laboratório de fitopatologia do Centro de Pesquisa Agropecuária do Trópico Úmido (Belém) .

A extração e identificação dos nematóides, a nível de gênero ou espécie, processaram-se de acordo com Freire (1976a).

( ${ }^{*}$ - Centro de Pesquisa Agropecuária do Trópico Úmido, Belém.

(*) - Departamento de Zoologia da Escola Superior de Agricultura "Luiz de Queiroz", Piracicaba. 


\section{RESUltados E DISCUSSÃo}

Os fitonematóides e os de vida livre, identificados nas diversas amostras de solo e raizes, encontram-se listados nos Quadros I e II, respectivamente.

Dentre as espécies de hábito parasitário associadas à pimenta-do-reino Meloidogyne incognita mostrou-se como a mais freqüente, seguindo-a as espécies Xiphinema brasiliense, Macrophostonia onoensis e $X$. attorodorum. Excetuando-se a espécie $M$. incognita, a qual já havia sido reportada parasitando a pimentado-reino no Estado do Pará (Lordello \& Silva, 1974; Ichinohe, 1976 e Freire, 1976), todas as demais expostas no Quadro I são, pela primeira vez assinaladas em associação a esta cultura na região amazônica. Outros gêneros e/ou espécies encontradas por Sharma \& Loof (1974) no Estado da Bahia, tais como Discocriconemella limitanea, Dolichodorus minor, Rotylenchulus reniformis, Trichodorus sp. e Xiphinema vulgare não foram identificadas neste levantamento em associação com a pimenta-do-reino.

Planta cloróticas desta cultura, e apresentando deficiente desenvolvimento vegetativo, foram observadas freqüentemente em cultivos com elevada infestação por nematóides das galhas, máxime $M$. incognita. Entretanto, a despeito da ampla dispersão e capacidade parasitária destes vermes, inúmeras plantas exibiam excelente aspecto vegetativo e produção, mesmo quando infestadas pelos nematóides em apreço. Possivelmente, isto deve-se ao fato de a cultura receber consideráveis quantidades de fertilizantes, assegurando-lhe condições de suportar elevadas populações nêmicas. Contudo, a par dos prejuizos que normalmente os nematóides podem determinar à pimenta-do-reino há de se considerrar, também, o aspecto da predisposição a outros agentes etiológicos, como por exemplo Fusarium solani $f$. piperis. Com efeito, no curso do presente levantamento observou-se uma freqüente associação entre $M$. incognita e o referido fungo, o qual foi por diversas vezes isolado do interior de galhas contendo aquela espécie de nematóides. Acresça-se, ademais, que as plantas já exibiam os sintomas típicos da podridão das raízes e do colo e que o fungo isolado revelou-se patogênico quando inoculado em estacas de pimenta-do-reino.

Com relação ao cacaueiro a espécie Dolichodorus minor foi encontrada em maior freqüência nas amostras examinadas, seguida de Xiphinema attorodoum, Macrophostonia onoensis e Peltamigratus christiei. Dos nematóides apresentados no Quadro I apenas encontrados em associação com o cacaueiro na região amazônica (Manço, 1973; Freire, 1976b). Os demais gêneros e/ou espécies são agora assinalados pela primeira vez nesta região do país. Os nematóides Boleodorus sp., Gracilacus aculentus; Helicotylenchus californicus, $H$. exallus, $H$. multicinctus, Longidorus sp., Tylenchorhynchus martini, Tylenchus devainei, Xiphinema americanum, $H$. ensiculiferum, $X$. setariae e $X$. vulgare, identificados por Sharma (1971), Sharma \& Sher $(1973 ;$ 1974) associados ao cacaueiro nos Estados da Bahia e Espírito Santo não foram encontrados durante as etapas deste levantamento. Ao contrário da

QUADRO I Fitonematódeos associados à pimenta -do-reino (Piper nigrum L.) e ao cacaueiro (Theobroma cacao L.) em municípios do Estado do Pará.

\begin{tabular}{|c|c|c|c|c|}
\hline \multirow{2}{*}{ NEMATÓDEOS } & \multicolumn{2}{|c|}{ HOSPEDEIROS } & \multicolumn{2}{|c|}{ OCORRENCIA * } \\
\hline & $\begin{array}{l}\text { Pimen- } \\
\text { ta-do- } \\
\text { reino }\end{array}$ & $\begin{array}{c}\text { Cacau- } \\
\text { eiro }\end{array}$ & $\begin{array}{l}\text { Pimen- } \\
\text { to-do- } \\
\text { reino }\end{array}$ & $\begin{array}{c}\text { Cacau- } \\
\text { eiro }\end{array}$ \\
\hline Dolichodorus minor & - & + & - & 42,4 \\
\hline Helicotylenchus sp. & + & + & 15,4 & 7,6 \\
\hline H. dihystera & + & + & 12,4 & 10,2 \\
\hline Hemicycliophora sp. & + & + & 3,1 & 2,2 \\
\hline $\begin{array}{l}\text { Hemicriconemoides sp. } \\
\text { Macrophostonia }\end{array}$ & + & + & 10,6 & 9,8 \\
\hline onoensis & + & + & 42,1 & 20,7 \\
\hline Meloidogyne arenaria & + & + & 2,1 & 1,8 \\
\hline M. incognita & + & + & 87,3 & 13,4 \\
\hline M. javanica & + & - & 6,1 & - \\
\hline Peltamigratus christiei & + & + & 2,4 & 19,7 \\
\hline Pratylenchus sp. & + & + & 1,6 & 1,2 \\
\hline Trichodorus sp. & 一 & + & - & 1,1 \\
\hline Tylenchus sp. & + & + & 2,0 & 1,8 \\
\hline $\begin{array}{l}\text { Tylenchorhynchus sp. } \\
\text { Xiphinema }\end{array}$ & + & + & 1,4 & 1,3 \\
\hline attorodorum & + & + & 39,7 & 28,9 \\
\hline X. brasiliense & + & + & 43,2 & - \\
\hline X. surinamense & - & + & - & 12,6 \\
\hline
\end{tabular}

(*) Percentogem nas amostras

$+\quad=$ presente

$-\quad=$ ausente 
pimenta-do-reino o cacaueiro nåo se mostra ainda tão afetado pelos nematóides em condições de campo. É provável que problemas relacionados com fitonematóides possam surgir em decorrência dos aumentos da área de plantio desta cultura na região amazônica e do nível populacional dos nematóides.

A partir de raízes fragmentadas e colocadas em água destilada foram obtidos, para ambas as culturas, exemplares dos gêneros $\mathrm{He}$ licotylenchus, Memicycliophora, Hemicriconemoides, Pratylenchus e Xiphinema.

Uma importante etapa do levantamento consistiu da identificação de alguns gêneros de nematóides de vida livre, os quais se encontram expostos no Quadro II. Não obstante serem pouco estudados, quando comparados aos fitonematóides, sabe-se que os mencionados nematóides podem disseminar, dentre outros organismos, bactérias e fungos fitopatogênicos, além de possuirem sistemas enzimáticos que lhes permitem o aproveitamento de células vegetais (Myer, 1965). De acordo com Paramonov (1968) alguns nematóides considerados de vida livre têm capacidade de se estabelecer e obter alimento em um organismo vegetal.

QUADRO II - Nematódeos de vida livre associados à pimenta-do-reino (Piper nigrum L.) e ao cacaueiro (Theobroma cacao L.) em municípios do Estado do Pará.

\begin{tabular}{l|c|c}
\hline & \multicolumn{2}{c}{ HOSPEDEIROS } \\
\cline { 2 - 3 } NEMAToDEOS & Pimenta-do-reino & Cacaueiro \\
\cline { 2 - 3 } & & + \\
\hline Alaimus sp. & + & + \\
Amphidelus sp. & - & + \\
Aphelenchus sp. & + & + \\
Axonchium sp. & - & + \\
Bastiania sp. & + & + \\
Belondira sp. & + & + \\
Boleodorus sp. & + & + \\
Cephalobus sp. & + & + \\
Cryptonchus sp. & - & + \\
Diphtherophora sp. & + & + \\
Dorylaimus sp. & + & + \\
Mononchus sp. & + & + \\
Rhabditis sp. & + & + \\
Zeldia sp. & - & + \\
\hline
\end{tabular}

$+=$ Presente

= Ausente
Para o caso específico da pimenta-do-reino não deve ser excluída a possibilidade de proteção e disseminação de esporos de Fusarium solani f. piperis por nematóides de vida livre. De acordo com Jensen \& Siemer $(1969,1971)$ uma espécie de nematóide do gênero Pristionchus foi capaz de disseminar, em seu intestino, esporos dos fungos Fusarium e Verticillium, protegendo-os da ação do cloro e tiabendazole, produtos aos quais os esporos são normalmente sensíveis. A transmissão de bactérias fitopatogênicas por diversos nematóides de vida livre foi também demonstrada por Jensen (1967).

\section{Conclusões}

A elevada população de fitonematóides identificados em associação à pimenta-do-reino e ao cacaueiro, a par da indiscutível importância econômica destas duas culturas para a região amazônica, sugerem maiores estudos com o intuito de avaliar, precisamente, os prejuízos decorrentes desta associação. Deve-se considerar, ademais, a interação entre nematóides parasitas e outros agentes etiológicos, além da possível disseminação de organismos patogênicos a ambas as culturas, através de nematóides de vida livre.

\section{SUMMARY}

In this second part of the taxonomic survey of nematodes is the Amazon Regios the authors show the plant - parasitic and free - living nematodes associated with black pepper (Piper nigrum L.) and cocoa plants (Theobroma cacao L.) in the State of Pará. A total of 6 genera and 10 species of plant - parasitic nematodes and 15 genera of free - living nematodes were characterized.

Most of them has never been found associated to those plants in the Amazon Region before.

\section{BIBLIOGRAFIA CITADA}

FreIRE, F.C.O.

1976a - Nematóides da região amazônica. I Nematóides parasitas e de vida livre associados à seringueira (Hevea brasiliensis Muell. Arg.) e ao guaraná (Paullinia cupana H.B.K. var. sorbilis (Mart.) Ducke). Acta Amazonica, 6(4) : 401-404. 
1976b - Nematóides das galhas, Meloidogyne spp., associados so parasitismo de plantas na regiắo amazônica. I - no Estado do Pará. Acta Amazonica, 6(4): 405-408.

ICHINOHE, M.

1976 - Infestation of black pepper by the root-knot nematode in Brazil. Japan Agric. Researc. Quartl., 10(1) : 17-20.

JENSEN, H.J.

1967 - Do saprozoic nematodes have a signifi. cant role in epidemiology of plant diseases? Plant Dis. Reptr., 5i(2) : 98-102.

JENSEN, H.J. \& SIEMER, S.R.

1969 - Protection of fungus spores from certain biocides following ingestion by saprozoic nematodes. Juur. Nematol., 1(1) : 12-13.

1971 - Protection of Fusarium and. Verticillium propagulos from selected biocides following ingestion by Pristionchus Iheritieri, Jour. Nematol., 3(1) : 23-27.

LORDELLO, L.G.E. \& Silva, H.M.

1974 - Um nematóide nocivo à pimenta-do-reino. Rev. Agric., 49(4) : 165-166.

Manço, G.R.

1973 - Consideraçōes gerais sobre as enfermidades do cacaueiro na Amazônia. Rev, Theobroma, 3(1):3-13.
MYERS, R.F.

1965 - Amylase, cellulase, invertase and pectinase in several free-living, mycophagus and plant-parasitic nematodes. Nematologia, $11: 441-448$.

PARAMONOV, A.

1968 - Plant - parasitic nematodes, Vol. I, U.S.D.A. and Nat. Sci. Found. ed., Washington, $390 \mathrm{p}$.

SHARMA, R.D.

1971 - Nematóides associados com o cacauei. ro e seringueira na Bahia. Rev. Theobroma, $1(3): 43-45$.

Sharma, R.D. \& LOOF, P.A.A.

1974 - Nematodes of the cocoa region of Bahia, Brazil. IV - Nematodes in the rhizospheres of pepper (Piper nigrum. L.) and clove (Eugenia' caryophyllata Thunb.), Rev. Theobroma, 4(3):26-32.

SHARMA, R.D. \& SHER, S.A.

1973 - Nematodes of the cocoa region of Bahia. Brazil. II - Ocurrence and distribution of plant-parasitic nematodes associated with cocoa (Theobroma cacao L.), Rev. Theobroma, 3(3) : 17-24.

1974 - Nematóides da regiăo cacaueira do Espírito Santo, Brasil. I - Nematóides associados ao cacaueiro (Theobroma cacao L.). Rev. Theobroma, 4(4) : 26-31.

(Aceito para publicação em 31/08/78) 